\title{
Hemoglobin A Measurement
}

National Cancer Institute

\section{Source}

National Cancer Institute. Hemoglobin A Measurement. NCI Thesaurus. Code C92258.

The determination of the amount of hemoglobin A present in a sample. 